\title{
Myricetin Inhibits Islet Amyloid Polypeptide (IAPP) Aggregation and Rescues Living Mammalian Cells from IAPP Toxicity
}

\author{
Casey Zelus ${ }^{\mathrm{a}}$, Ayano Fox ${ }^{\mathrm{a}}$, Anastasia Calciano ${ }^{\mathrm{a}}$, Bianca S. Faridian ${ }^{\mathrm{b}}$, Luiza A. Nogaj ${ }^{\mathrm{b}}$ and David $^{-}$ \\ A. Moffet ${ }^{\mathrm{a}^{*}}$ \\ ${ }^{a}$ Department of Chemistry and Biochemistry, Loyola Marymount University, 1 LMU Drive Los Angeles, CA 90045, USA \\ ${ }^{b}$ Department of Biology, Mount Saint Mary's College 12001 Chalon Rd, Los Angeles, CA 90049, USA
}

\begin{abstract}
The aggregation of the amyloidogenic polypeptide IAPP (Islet Amyloid Polypeptide, amylin) is believed to play a direct role in the death of pancreatic $\beta$-islet cells in type II diabetes. Preventing the initial aggregation event of IAPP is one strategy for slowing, and possibly preventing, the progression of this disease. Here, we investigate myricetin's potential as an inhibitor of IAPP aggregation. We show that myricetin prevented thioflavin T binding in a concentration dependent manner. Atomic force microscopy revealed that myricetin prevented fiber formation under rigorous conditions conducive to forming IAPP aggregates. Using an IAPP-EGFP (Enhanced Green Fluorescent Protein) protein construct, we find that high concentrations of myricetin slowed the in vivo aggregation of IAPP-EGFP. Myricetin was also found to rescue living mammalian cells from the toxic effects of IAPP. These results indicate that myricetin is a strong inhibitor of IAPP amyloid aggregation and a potential lead molecule for the development of an amyloid inhibiting therapeutic.
\end{abstract}

Keywords: Type 2 diebetes, amyloid, amylin.

The aggregation of misfolded proteins has been directly linked to diseases such as type II diabetes, Alzheimer's disease and Parkinson's disease. It is believed that in each case, a protein misfolds and self-assembles into toxic oligomers and fibers, ultimately forming insoluble amyloid. While these amyloidogenic proteins differ from each other in many ways, such as amino acid composition, protein length and organismal localization, those proteins appear to fold into $\beta$ sheet structures that ultimately form toxic species. Even unnatural proteins, designed to fold into $\beta$-sheet structures, appear to progress through similar pathways to form toxic amyloid species [1]. The misfolded amyloid protein found in the pancreas of individuals afflicted with type II diabetes is the 37-amino acid polypeptide IAPP (islet amyloid polypeptide, amylin). While the exact role of IAPP in type II diabetes is unclear, insoluble IAPP is found in the extracellular deposits of amyloid in approximately $95 \%$ of patients afflicted with type II diabetes [2-4]. IAPP has also been shown to be a toxic agent in vitro when added to human islet $\beta$-cells [5].

One therapeutic strategy for preventing or slowing the progression of amyloid diseases such as type II diabetes, is to inhibit the aggregation of the amyloidogenic proteins. It is believed that preventing the initial aggregation event could prevent the formation of toxic oligomers and fibers. Several polyphenol compounds have been shown to act as inhibitors of peptide aggregation for the amyloidogenic proteins $A \beta$

*Address correspondence to this author at the Department of Chemistry and Biochemistry, Loyola Marymount University, 1 LMU Drive Los Angeles, CA 90045, USA; Tel: 310-338-4400; Fax: 310-338-2905;

E-mail: dmoffet@lmu.edu. and tau (involved in Alzheimer's disease) and $\alpha$-synuclein (in Parkinson's disease) [6-8]. Recently, several polyphenols have been shown to inhibit IAPP aggregation $[9,10]$. Here we describe the ability of myricetin (Fig. 1) to inhibit the aggregation of IAPP in a concentration dependent manner. More importantly, we describe the ability of myricetin to rescue mammalian cells from the toxic effects of IAPP.

To test myricetin's ability to inhibit IAPP aggregation, ThT-binding experiments were performed. When dissolved in an aqueous solution, ThT has negligible fluorescence emission when irradiated with $450 \mathrm{~nm}$ light. However, ThT fluorescence increases drastically upon binding to amyloid fibrils [11]. Synthetic IAPP (GenScript Corp.) was first disaggregated in HFIP (Sigma) in a sonicating water bath. HFIP was removed over a steady stream of dry nitrogen gas. The resulting peptide sample was dissolved in $20 \mathrm{mM}$ tris buffer pH 7.40 to yield an IAPP in-solution concentration of 106 $\mu \mathrm{M}$. Myricetin (Sigma) was dissolved in ethyl acetate and added to various in-solution concentrations (all samples contained equivalent ethyl acetate concentrations). Aggregation<smiles>O=c1c(O)c(-c2cc(O)c(O)c(O)c2)oc2cc(O)cc(O)c12</smiles>

Fig. (1). Chemical structure of myricetin. 
was promoted by incubating samples at $37^{\circ} \mathrm{C}$ with shaking $(200 \mathrm{rpm})$. An aliquot of each sample was removed at indicated time points and mixed with $12.0 \mu \mathrm{M}$ thioflavin $\mathrm{T}$ in 20 $\mathrm{mM}$ Tris buffer $\mathrm{pH}$ 7.40. The thioflavin T mixture was incubated at room temperature in the dark for 5 minutes before recording the thioflavin $\mathrm{T}$ fluorescence emission spectrum $\left(\mathrm{Ex}_{450 \mathrm{~nm}}\right)$ using a Hitatchi F-7000 fluorescence spectrophotometer.

IAPP is one of the most amyloidogenic peptides known. Under these aggregation-promoting conditions, IAPP began to bind ThT in less than 15 minutes of incubation (Fig. 2). In the presence of myricetin, ThT binding was reduced in a concentration-dependent manner. At the highest concentration of myricetin tested, where myricetin was at a 10 -fold molar excess over IAPP, the ThT-binding of IAPP was approximately the same as ThT in solution in the absence of IAPP. The decrease in ThT fluorescence after reaching its maximum is commonly witnessed in these assays and is consistent with previously reported amyloid aggregation reactions $[12,13]$.

AFM experiments showed that IAPP incubated under the aggregation-promoting conditions described above produced

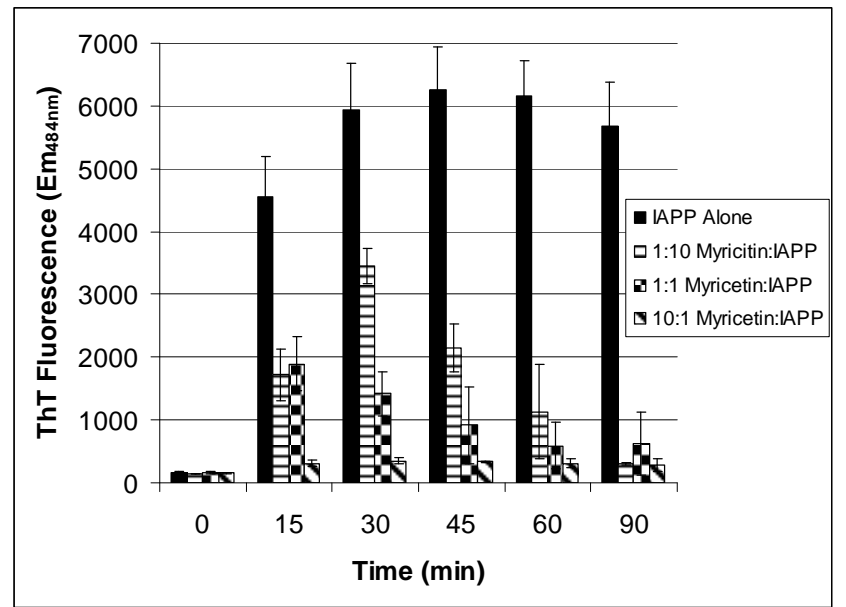

Fig. (2). ThT binding of IAPP in the presence of various concentrations of myricetin. IAPP was $106 \mu \mathrm{M}$ for all samples. The 1:10 sample contained $10 \mu \mathrm{M}$ myricetin, the 1:1 sample contained 100 $\mu \mathrm{M}$ myricetin and the 10:1 sample contained $1 \mathrm{mM}$ myricetin. Error bars represent the standard deviation of four separate trials.

a variety of different insoluble aggregates (Fig. 3). Under these conditions, IAPP alone formed insoluble fibrils of var-



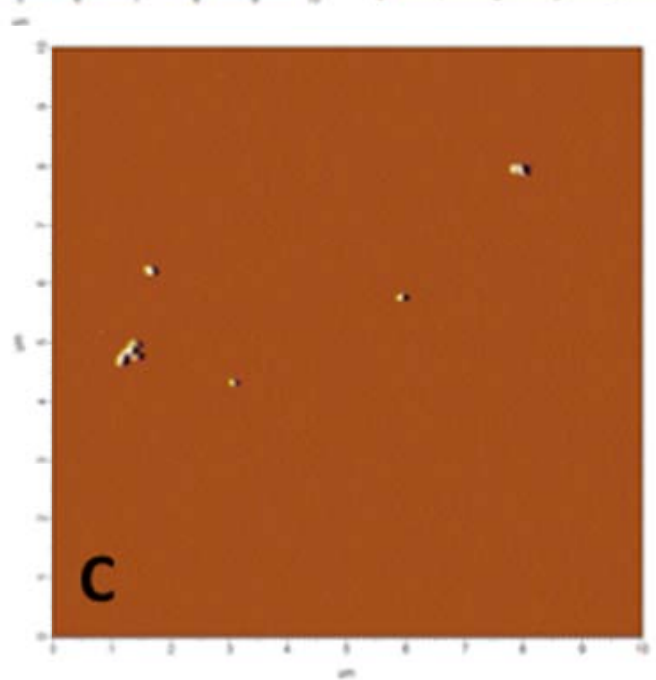

Fig. (3). Atomic force microscopy images of $106 \mu \mathrm{M}$ IAPP (A) alone (B) with a 1:1 ratio of myricetin and (C) with a 10:1 molar excess of myricetin. Samples were incubated at $37^{\circ} \mathrm{C}$ for 45 minutes with vigorous shaking. 
ious lengths, as well as yielded a preponderance of amorphous aggregates. When IAPP was incubated with a 10 -fold molar excess of myricetin, virtually no insoluble aggregates were detected (Fig. 3). Under no conditions tested were we able to detect IAPP fibers when IAPP was incubated with a 10x molar excess of myricetin.

The use of fluorescent protein fusions to amyloidogenic proteins has been shown to be an effective method for distinguishing relative levels of amyloidogenicity [14-20]. We constructed an IAPP-EGFP fusion protein for expression in E. coli [21]. Aggregation of the IAPP precludes folding, and hence fluorescence, of the EGFP fusion protein. Substances that prevent or slow IAPP aggregation allow the EGFP protein to fold and fluoresce. E. coli cells were induced with 1 $\mathrm{mM}$ IPTG to express the IAPP-EGFP protein construct. Cells were incubated at $37^{\circ} \mathrm{C}$ with shaking in the absence and presence of myricetin (Fig. 4). Fluorescence intensity of the EGFP was highest when cells were incubated with $1 \mathrm{mM}$ myricetin. Cells incubated without myricetin, or low concentrations of myricetin, showed less EGFP fluorescence.

To test the potential of myricetin to protect living cells from IAPP, PC12 cells were incubated with $10 \mu \mathrm{M}$ of synthetic IAPP (Fig. 5). The PC12 cells were cultured in 5\% $\mathrm{CO}_{2}$ at $37^{\circ} \mathrm{C}$ in F-12K media (ATCC) supplemented with $10 \%$ FBS (ATCC). The cells were plated in 96-well plates. After a twenty-four hour incubation, the F12-K media was substituted for DMEM/F12 (1:1) without phenol red and supplemented with $10 \%$ FBS $(100 \mu \mathrm{L}$ total volume/well). IAPP at $10 \mu \mathrm{M}$ and/or myricetin at $10 \mu \mathrm{M}$ or $50 \mu \mathrm{M}$ was added to the appropriate wells and incubated for 22 hours at 37I C. MTT, dissolved at $0.3 \mathrm{mg} / \mathrm{mL}$ in DMEM without phenol red, was added to each well $(10 \mu \mathrm{L} /$ well $)$ and incu-



Fig. (4). Relative fluorescence intensity of $E$. coli expressing IAPPEGFP either alone or in the presence of myricetin. All samples show the fluorescence of E. coli expressing IAPP-EGFP. The fluorescence increases when the $E$. coli are incubated with a high concentration of myricetin. Error bars represent the standard deviation of three separate trials.

bated for 2 hours at $37^{\circ} \mathrm{C}$. The purple formazan crystals were dissolved using a solubilization buffer (50\% dimethylformamide and $20 \%$ SDS in water). The absorbance of each well was measured at $575 \mathrm{~nm}$ with a BioRad 550 microplate reader. Myricetin is only partially soluble in water, requiring DMSO for full solubilization.

The MTT assay, which quantitates the oxidative capacity of PC12 cells after treatment with IAPP alone, IAPP and myricetin, and myricetin alone, indicated that myricetin rescued the living cells from the toxic effects of IAPP. IAPP at



Fig. (5). The effect of myricetin on the toxicity of IAPP in PC12 cells. Each well contained an equal density of PC12 cells. The MTT viability assay was performed in triplicate. Each set of samples was calculated as a percentage of the control (cells alone). Error bars represent the standard deviation of the three separate assays. 
$10 \mu \mathrm{M}$ was toxic to the cells and reduced the MTT signal to $71 \%$ compared to cells untreated with IAPP. At a 1 to 1 ratio of myricetin to IAPP, the cells were rescued back to $90 \%$ compared to untreated cells. At a ratio of 5:1 myricetin to IAPP, the cells were rescued to an MTT signal $>96 \%$ compared to untreated cells. Myricetin alone was found to have some effect on the PC12 cells. We found that a 5 fold excess of Myricetin alone (in the absence of IAPP) showed a $20 \%$ decrease in cellular viability. However, the combination of myricetin+DMSO was found to rescue the PC12 cells from IAPP, suggesting the interaction between myricetin and IAPP precludes toxicity of either myricetin or IAPP.

IAPP is a highly amyloidogenic protein directly linked to pancreatic $\beta$-cell death in type 2 diabetes. Our results show myricetin to be a strong inhibitor of IAPP amyloidogenic fiber formation. Insoluble IAPP aggregation was undetectable with either ThT binding or AFM when myricetin was incubated at a 10 -fold molar excess with IAPP. This inhibition of IAPP aggregation was found to be dependent on the concentration of myricetin used. Myricetin was also found to inhibit IAPP aggregation in vivo, allowing the IAPP-EGFP fusion protein to fluoresce. Finally, myricetin was found to rescue living mammalian cells from the effects of toxic IAPP. These results indicate that myricetin is a potent inhibitor of IAPP amyloid formation and a potential therapeutic lead for the treatment of amyloid diseases such as type 2 diabetes.

\section{ABBREVIATIONS}

$\begin{array}{lll}\text { IAPP } & = & \text { Islet Amyloid Polypeptide } \\ \mathrm{ThT} & = & \text { thioflavin } \mathrm{T} \\ \mathrm{HFIP} & = & \text { hexafluoroisopropanol } \\ \mathrm{AFM} & = & \text { atomic force microscope } \\ \mathrm{EGFP} & = & \text { enhanced green fluorescent protein } \\ \mathrm{IPTG} & = & \text { Isopropyl } \beta \text {-D-1-thiogalactopyranoside }\end{array}$

\section{ACKNOWLEDGEMENTS}

This work was funded in part by NIH AREA grant R15DK094273-01.

We thank the LMU Seaver College of Science and Engineering and the LMU Women's Leadership Council for support of this project.

\section{CONFLICT OF INTEREST}

None declared.

\section{REFERENCES}

[1] Olzscha, H.; Schermann, S. M.; Woerner, A. C.; Pinkert, S.; Hecht, M. H.; Tartaglia, G. G.; Vendruscolo, M.; Hayer-Hartl, M.; Hartl, F. U.; Vabulas, R. M. Amyloid-like aggregates sequester numerous metastable proteins with essential cellular functions. Cell, 2011, 144, 67-78.

[2] Apostolidou, M.; Jayasinghe, S. A.; Langen, R. Structure of alphahelical membrane-bound human islet amyloid polypeptide and its implications for membrane-mediated misfolding. J. Biol. Chem., 2008, 283, 17205-17210.

[3] Hull, R. L.; Westermark, G. T.; Westermark, P.; Kahn, S. E. Islet amyloid: a critical entity in the pathogenesis of type 2 diabetes. $J$. Clin. Endocrinol. Metab., 2004, 89, 3629-3643.

[4] Kahn, S. E.; Andrikopoulos, S.; Verchere, C. B. Islet amyloid: A long-recognized but underappreciated pathological feature of type 2 diabetes. Diabetes, 1999, 48, 241-253.

[5] Ritzel, R. A.; Meier, J. J.; Lin, C. Y.; Veldhuis, J. D.; Butler, P. C. Human islet amyloid polypeptide oligomers disrupt cell coupling, induce apoptosis, and impair insulin secretion in isolated human islets. Diabetes, 2007, 56, 65-71.

[6] Porat, Y.; Abramowitz, A.; Gazit, E. Inhibition of amyloid fibril formation by polyphenols: structural similarity and aromatic interactions as a common inhibition mechanism. Chem. Biol. Drug Des., 2006, 67, 27-37.

[7] Ono, K.; Yoshiike, Y.; Takashima, A.; Hasegawa, K.; Naiki, H.; Yamada, M. Potent anti-amyloidogenic and fibril-destabilizing effects of polyphenols in vitro: implications for the prevention and therapeutics of Alzheimer's disease. J. Neurochem., 2003, 87, 172181.

[8] Taniguchi, S.; Suzuki, N.; Masuda, M.; Hisanaga, S.; Iwatsubo, T.; Goedert, M.; Hasegawa, M. Inhibition of heparin-induced tau filament formation by phenothiazines, polyphenols, and porphyrins. $J$. Biol. Chem., 2005, 280, 7614-7623.

[9] Meng, F. L.; Abedini, A.; Plesner, A.; Verchere, C. B.; Raleigh, D. P. The Flavanol (-)-Epigallocatechin 3-gallate inhibits amyloid formation by islet amyloid polypeptide, disaggregates amyloid fibrils, and protects cultured cells against iapp-induced toxicity. Biochemistry, 2010, 49, 8127-8133.

[10] Noor, H.; Cao, P.; Raleigh, D. P. Morin hydrate inhibits amyloid formation by islet amyloid polypeptide and disaggregates amyloid fibers. Protein. Sci., 2012, 21, 373-382.

[11] Levine, H. 3rd. Thioflavine $T$ interaction with synthetic Alzheimer's disease beta-amyloid peptides: detection of amyloid aggregation in solution. Protein Sci., 1993, 2, 404-410.

[12] Yamin, G.;Ruchala, P.Teplow, D.B. A Peptide Hairpin Inhibitor of Amyloid beta-Protein Oligomerization and Fibrillogenesis. Biochemistry, 2009, 48, 11329-11331.

[13] Ahn, J. S.; Lee, J. H.; Kim, J. H.; Paik, S. R. Novel method for quantitative determination of amyloid fibrils of alpha-synuclein and amyloid beta/A4 protein by using resveratrol. Anal. Biochem., 2007, 367, 259-265.

[14] Baine, M.; Georgie, D. S.; Shiferraw, E. Z.; Nguyen, T. P. T.; Nogaj, L. A.; Moffet, D. A. Inhibition of A beta 42 aggregation using peptides selected from combinatorial libraries. J. Pept. Sci., 2009, 15, 499-503.

[15] De Groot, N. S.; Aviles, F. X.; Vendrell, J.; Ventura, S. Mutagenesis of the central hydrophobic cluster in A beta 42 Alzheimer's pepticle - Side-chain properties correlate with aggregation propensities. FEBS J., 2006, 273, 658-668.

[16] Kim, W.; Kim, Y.; Min, J.; Kim, D. J.; Chang, Y. T.; Hecht, M. H. A high-throughput screen for compounds that inhibit aggregation of the Alzheimer's peptide. ACS Chem. Bio., 2006, 1, 461-469.

[17] Wurth, C.; Guimard, N. K.; Hecht, M. H. Mutations that reduce aggregation of the Alzheimer's Abeta42 peptide: an unbiased search for the sequence determinants of Abeta amyloidogenesis. $J$. Mol. Biol., 2002, 319, 1279-1290.

[18] Wurth, C.; Kim, W.; Hecht, M. H. Combinatorial approaches to probe the sequence determinants of protein aggregation and amyloidogenicity. Protein Pept. Lett., 2006, 13, 279-286.

[19] Kim, W.; Hecht, M. H. Generic hydrophobic residues are sufficient to promote aggregation of the Alzheimer's A beta 42 peptide. Proc. Natl. Acad. Sci. USA, 2006, 103, 15824-15829.

[20] Kim, W.; Hecht, M. H. Mutations enhance the aggregation propensity of the Alzheimer's A beta peptide. J. Mol. Biol., 2008, 377, 565-574. 
[21] Fox, A.; Snollaerts, T.; Casanova, C. E.; Calciano, A.; Nogaj, L. A.; Moffet, D. A. Selection for Nonamyloidogenic Mutants of Islet
Amyloid Polypeptide (IAPP) Identifies an Extended Region for Amyloidogenicity. Biochemistry, 2010, 49, 7783-7789.

(C) Zelus et al.; Licensee Bentham Open.

This is an open access article licensed under the terms of the Creative Commons Attribution Non-Commercial License (http://creativecommons.org/licenses/by-nc/3.0/) which permits unrestricted, non-commercial use, distribution and reproduction in any medium, provided the work is properly cited. 